\title{
Methodical Approaches to the Study of Human Chromosomal Q-Heterochromatin Variability
}

\author{
Ibraimov A. I. ${ }^{1}$ \\ ${ }^{1}$ Institute of Balneology and Physiotherapy, Bishkek and Laboratory of Human Genetics, National Center of \\ Cardiology and Internal Medicine, Bishkek, Kyrgyzstan \\ Correspondence: Ibraimov A. I., Institute of Balneology and Physiotherapy, Bishkek and Laboratory of Human \\ Genetics, National Center of Cardiology and Internal Medicine, Bishkek, Kyrgyzstan. E-mail: \\ ibraimov_abyt@mail.ru
}

Received: November 20, 2015 Accepted: December 9, 2015 Online Published: December 12, 2015

doi:10.5539/jmbr.v6n1p1 URL: http://dx.doi.org/10.5539/jmbr.v6n1p1

\begin{abstract}
In spite of the fact that chromosomal Q-heterochromatin regions (Q-HRs) in the genome have been opened almost half a century ago, we still know extremely few of their possible roles in the human life activity. One of the reasons of such state is the lack of methodical approaches mostly suitable to the nature and features for chromosomal Q-HRs. In the present work the existing methodical approaches of the human chromosomal Q-HRs has been analyzed, beginning from empirical observations up to the analytical approaches, aimed to detect regularities of Q-HRs distribution and possible effects at population level, in norm and pathology. It is appeared, that all depends on how we consider the nature of chromosomal Q-HRs, namely, whether they are structurally uniform formations in genome or their possible effects depend on features of Q-HRs localization on this or that chromosome in the human karyotype.
\end{abstract}

Keywords: Q-heterochromatin, C-heterochromatin, genetic system, human body heat conductivity, human adaptation

\section{Introduction}

The fact that chromosomes of the higher eukaryotes consists of two important components - euchromatin and heterochromatin - has been determined in the thirties years of the $20^{\text {th }}$ century (Heitz, 1928, 1934, 1935). In the seventies of the last century it has been found out, that there are, at least, two kinds of constitutive heterochromatin: C-heterochromatin, existing in genome in all of the higher eukaryotes and Q-heterochromatin, which can be found out in genome only in three higher primacies (Homo s. sapiens, Pan troglodytes and Gorilla gorilla) (Caspersson et al., 1970; Paris Conference, 1971, 1975; Pearson, 1973, 1977; ISCN, 1978).

There is the huge literature devoted to study of microscopic structure, molecular composition, methods of identification and a quantitative estimation of chromosomal C-heterochromatin areas (C-HRs) in karyotype, detailed in a number of reviews (Schmid, 1967; Prokofyeva-Belgovskaya, 1986; Verma \& Dosik, 1980a; Stahl \& Hartung, 1981; Ibraimov \& Mirrakhimov, 1985; John, 1988; Verma, 1988; Bhasin, 2007). The present work considers the same questions regarding human chromosomal Q- heterochromatin regions (Q-HRs). Therefore we will start with results of the first empirical observations which have been based into all subsequent analytical works, aimed at searches of a possible biological role of chromosomal Q-HRs in the human genome.

\section{Empirical researches}

The early 1970's witnessed the development of several new cytochemical methods for studying microscopically certain types of constitutive heterochromatin directly in chromosome preparations (Paris Conference, 1971, 1975; ISCN, 1978). One of the important results of such studies was the discovery of genetic polymorphism at the chromosomal level due to the high variability of the heterochromatic regions. We owe the discovery of Q-heterochromatin polymorphisms to a group of scientists at the Karolinska Institute in Stockholm headed by the noted Swedish cytologist T. Caspersson (Caspersson et al., 1970), who were able to show that by using appropriate methods to stain chromosome preparations with quinacrine mustard a remarkable picture could be seen under a fluorescent microscope: each homologous pair of metaphase chromosomes has an individual pattern of differential fluorescence by which it can be identified. These authors showed that individual areas of certain chromosomes 
vary considerably in their intensity of fluorescence; specifically, that there are bands with particularly brilliant fluorescence in the centromeric region of chromosome 3, the short arms of acrocentric chromosomes 13-15, and the distal portion of the long arm of the Y chromosome. Evans and co-workers (1971) found similar brilliantly fluorescent areas on autosome pairs 21 and 22. It is now firmly established that brilliantly fluorescent polymorphic areas can be found only on seven autosomes - 3, 4, 13-15, 21, 22, and the Y chromosome. Later, at the Paris Conference on Standardization in Human Cytogenetics it was recommended that this method be termed Q-staining (from quinacrine mustard), and that fluorescence chromosomal bands be called Q-bands (Paris Conference, 1971, 1975; ISCN, 1978).

Unlike C-heterochromatin, Q-heterochromatin is not always apparent. C-heterochromatin is known to be present in absolutely all the 46 chromosomes of the human karyotype, varying only in size and location. In contrast, Q-heterochromatin may be completely absent in any of these chromosomes without any appreciable pathologic or other phenotypic consequences to the carrier, whereas complete absence of C-heterochromatin even in one chromosome is an extremely uncommon occurrence (Paris Conference, 1971, 1975).

Appropriate studies have shown that Q- and C-heterochromatin variants sometimes differ in both their location and their size in those chromosomes where they are located in the same regions (the $\mathrm{Y}$ chromosome, chromosome 3 , and the short arms of acrocentric chromosomes (Verma \& Dosik, 1980b). C-heterochromatin is known to account for $15-29 \%$ of the human genome. According to some authors, heterochromatic Q-band variants of a certain class may be completely absent in a considerable portion of a human population (Yamada \& Hasegawa, 1978; Al-Nassar et al., 1981; Ibraimov \& Mirrakhimov, 1982a,b,c, 1985; Ibraimov et al., 1982, 1986). Thus, there is ample evidence of significant qualitative and quantitative differences between regions of Q- and C-heterochromatin.

The chief morphologic expression of Q-heterochromatin polymorphism in differences among individuals in a given population in the presence, fluorescence intensity, size, and location of Q-heterochromatin in 12 polymorphic loci of seven autosomes (3p11q11, 4p11q11, 13p11, 13p13, 14p11, 14p13, 15p11, 15p13, 21p11, $21 \mathrm{p} 13,22 \mathrm{p} 11,22 \mathrm{p} 13$ ) and in the $\mathrm{q} 12$ band of the chromosome Y. It should be emphasized that there is no individual in human population who has Q-heterochromatin in all the 13 potentially polymorphic loci. The number of Q-heterochromatin variants usually range from 0 to 10 (Ibraimov, 2010, 2015; Ibraimov \& Mirrakhimov, 1982a,b,c, 1985; Ibraimov et al., 1982; 1986; 2013; 2014). After Q-staining, brilliant fluorescence (Q-heterochromatin) is usually seen on one-half to two-thirds of the long arm of the Y. It is the variable size of the brilliantly fluorescent band (q12) of the long arm of the $\mathrm{Y}$ that mainly accounts for the polymorphism in this chromosome (Paris Conference, 1971; 1975).

At the stage of empirical researches basically the questions of identification, the account and registration of variants of chromosomal Q-HRs have been studied. The matter is that the discovery of chromosomal polymorphism in man after Q-staining necessitated the development of a rational and unified system of recording Q-heterochromatin variants, primarily quantitative, for subsequent statistical analysis. Comparison of the frequency of various types of Q-variants in different populations (normal, pathologic, age group, ethnic groups, etc.) and assessment of their possible adaptive value are the most important problems in any study on human chromosomal polymorphism.

Currently the following quantitative measures of chromosomal Q-heterochromatin polymorphism in human populations:

- The frequency of Q-HRs in 12 potentially polymorphic loci of seven autosomes. It is usually expressed in percentages of the number of chromosomes analyzed, separately for each polymorphic locus;

- The distribution of Q-HRs in a population, i.e., distribution of individuals having different numbers of Q-HRs in the karyotype regardless of the location (distribution of Q-HRs), which also reflected the range of Q-HRs variability in the population genome;

- The mean number of chromosomal Q-HRs per individual, as determined by dividing the total number of Q-HRs detected in a given sample by the number of individuals studied;

- The size of the $\mathrm{Y}$ chromosome, being (a) large $(\mathrm{Y}=\mathrm{F})$, (b) medium ( $\mathrm{F}>\mathrm{Y}>\mathrm{G})$, and (c) small $(\mathrm{Y}=\mathrm{G})$.

Various aspects of the heritability of human chromosomal Q-HRs variability detected at this stage of researches. The heritability of Q-HRs variants has been the object of several studies. Phillips (1977) studied the pattern of inheritance of Q- and C-HRs variants in 36 subjects in three unrelated families and found that $50 \%$ of the offspring inherited chromosomes having polymorphic variants. Robinson et al., (1976) studied the segregation pattern of polymorphic chromosomes in 32 families and found that, on the whole, there was complete agreement of actual 
data with those predicted by Mendelian law. Similar conclusions were also drawn by other investigators (McKenzie \& Lubs, 1975; Tupitsina \& Stobetsky, 1980).

Thus, at the stage of empirical observations it was possible to find out: 1) localization of chromosomal Q-HRs in the human karyotype and methods of their identification; 2) existence of morphological variants of chromosomal Q-HRs in a human population; 3) mode chromosomal Q-HRs inheritance in the raw of generations; 4) to standardize the variants of chromosomal Q-HRs (Paris Conference, 1971; 1975; ISCN, 1978), required for comparative population researches. Thus, thanks to empirical observations it was possible to find out existence of wide variability of chromosomal Q-HRs in genome of human populations. Though these works have not opened the role of chromosomal Q-HRs in the human life activity, they have allowed beginning the systematic researches aimed to find out biological role of Q-HRs in evolution and development of the higher primacies.

\section{Analytical researches}

There is no agreement as to the nature of chromosomal Q-HRs variability, although all arguments are based on the 'selectionist' hypothesis. One approach, implying that Q-heterochromatin with different locations is basically similar in structural and functional features, as defined by us (Ibraimov et el., 1986; 1990) in the following manner: 'of primary importance to an individual is the dose and not the location of Q-variants'. The term 'dose' is defined as the amount of Q-heterochromatin material in the genome regardless of its location in any chromosome. In other words, this approach is based on the assumption that chromosomal Q-HRs lack locus-specificity. Those favoring the alternative approach believe that derivations from expected Q-HRs frequencies, observed in any loci, reflect some structural and functional features of these loci and are due either to selection or to non-fortuitous segregation of chromosomes bearing the given Q-HRs (Geraedts \& Pearson, 1974; Mikelsaar et al., 1975; Nazarenko, 1987).

Let's begin with the analysis of the second as we conditionally name, a locus specific approach. The supporters of such approach in the obvious or latent form mean, that Q-HRs, localized on different chromosomes in the human karyotype, represent different by its properties and biological effects hereditary structures. This is evidenced by the researches, where the authors pay paramount attention to frequencies of homo $(+/+$ or $-/-)$ and heterozygotes $(-/+)$ of chromosomal Q-HRs in population; namely the agreement of observed homo- and heterozygote frequencies in a population with those predicted by the law of Hardy-Weinberg. Though there are no direct instructions in the texts of these researches, that authors at this draw an analogy with the well-known HbS (as at sickle-cell anemia), nevertheless, judging by the method of the selected statistical analysis it is difficult to exclude such possibility.

It should be noted that frequencies of homo- and heterozygous chromosomal Q-HRs variants were not studied by all investigators in terms of the Hardy-Weinberg law. Nevertheless, there are many published studies in which the authors have performed a detailed analysis of the agreement of observed frequencies and those predicted by this fundamental law of population genetics (Schnedl, 1971; Inuma et al., 1973; Mikelsaar et al., 1974; Geraedts \& Pearson, 1974; Muller et al., 1975; Buckton et al., 1976; Van Dyke et al., 1977; Al-Nassar et al., 1981; Ibraimov \& Mirrakhimov, 1982a,b,c; Ibraimov et al., 1982; Stanyon et al., 1987; Kalz et al., 2005; Decsey et al., 2006). Agreement was found in most cases. However, several authors found some discrepancy between observed and predicted frequencies of certain Q-HRs variants in the seven autosomes. We decided not to examine these observations in detail, since the reasons for these discrepancies between observed homo- and heterozygote frequencies and those predicted by the Hardy-Weinberg law are unknown. Therefore, we shall only list the hypothetical explanations for these discrepancies suggested by the authors of these studies: 1. Methodological difficulties involved in the calculation of Q-HRs variants; 2. Sample sizes, since the Hardy-Weinberg law is known to be valid only for a large, randomly mated population; 3. Natural selection in the case of excess heterozygotes in a population in certain polymorphic loci (Geraedts \& Pearson, 1974; Mikelsaar et al., 1974; Müller et al., 1975; Bobinson et al., 1976; Tupitsina \& Stobetsky, 1980).

We found no statistically significant deviations between observed homo- and heterozygote frequencies and those predicted by the Hardy-Weinberg law even in those cases where: 1) the sample consisted of no more than 40 subjects; 2) the population had a long term exposure to extreme climate conditions (the extreme North of the Eastern Siberia or high altitudes of Pamir and Tien-Shan); or 3) a relatively high level of inbreeding had occurred (Ibraimov \& Mirrakhimov, 1982a,b,c; 1985; Ibraimov et al., 1982, 1986). Jacobs (1977) is of the opinion that it is premature to test the agreement of observed homo- and heterozygote frequencies with those predicted by the Hardy-Weinberg law, since methods of calculation of the Q-band variants are not sufficiently accurate because of the continuous nature of the size distribution of the Q-HRs in a population.

In order to investigate the possible role of Q-HRs variants in the development of malignant diseases, Kivi and Mikelsaar (1981) studied 37 female patients with ovarian or breast cancer and 150 normal female subjects of the same age. The following parameters were evaluated in both groups: the frequency of Q-HRs variants in seven 
autosomes, the mean number of brilliantly fluorescent Q-bands, and the frequency of inverted chromosome 3. Their results showed that the presence of Q-polymorphic variants was not associated with the high risk of developing ovarian or breast cancer. Mikelsaar et al. (1981) attempted to establish a correlation between Q-heterochromatin chromosomes and the variability in stature by studying Q-polymorphism in 589 normal Estonian subjects (180 males and 409 females). The subjects were classified homo- or heterozygotes according to each Q-polymorphic band analyzed, and each Q-polymorphic band was investigated in relation to stature. The authors were unable to find any statistically significant correlation between Q-HRs polymorphism and stature in females. However, such a correlation was observed in males for bands 13p11, 21p11, 22p11, and 22p13. Also heterozygous males were consistently taller on the average than homozygous males.

The study history of inversion of Q-heterochromatin segment of the human chromosome 3 is the other bright example of the locus specific approach to find out the chromosomal Q-HRs possible role in the human life activity. Allderdice (1973) was the first to describe pericentric inversion of the Q-heterochromatin band in chromosome 3 (inv 3) (p15q12) in two phenotypically normal subjects. Later, Soudek et al. (1974) found such an inverted chromosome 3 in three mentally deficient patients. After further investigations on sibs of these patients with inv 3 authors proposed to regard this variable chromosome 3 as a polymorphic feature. Subsequently, Soudek and Sroka (1978) studied the frequency of inv 3 in 370 mentally deficient patients and 222 mentally normal subjects. The frequency of inv 3 was found to be $4.05 \%$ in the former and $4.32 \%$ in the latter. These authors investigated the segregation of inv 3 in six families and found no significant deviation from the mendelian distribution. Mikelsaar et al. (1978) came to the same conclusion after a comparative study of 102 normal newborns and 45 mentally deficient subjects of Estonian nationality.

Fogle and McKenzie (1980) studied a large black family consisting of 83 members and covering four generations and found inv 3 in 23 of them, this inversion occurring in in a homozygous form in three of those affected. Those authors found no noticeable mental or other pathologic deviations in any of the 23 members of this family who exhibited inv 3 both in hetero- and the homozygous form. Kivi and Mikelsaar (1981) studied 74 female subjects with malignant breast and ovarian tumors and 80 healthy female subjects and found no differences in this parameter ( $8.1 \%$ and 7.5 , respectively), a finding that is in good agreement with data obtained previously in their laboratory during evaluation of the frequency of inv 3 in an Estonian population.

Verma and Dosik (1980b) performed a comparative analysis of Q- and C-bands in chromosome 3 after QFQ and CBG staining (ISCN, 1978). In several cases the authors found complete agreement in the location and sizes of Qand C-HRs variants. However, they observed cases where this polymorphic area of chromosome 3 failed to show any intense fluorescence despite the fact that CBG staining revealed the presence of a C-band and vice versa. This observation led the authors to conclude that these two methods of staining (QFQ and CBG) of chromosomes yield different information of heterochromatin polymorphisms of chromosome 3 .

Soudek and Sroka (1978) were right in pointing out that this interesting cytogenetic marker does not always receive due attention in comparative population studies. Therefore, in all the populations of Eurasia and Africa studied we accurately recorded the frequency of inv 3. Among all the populations we studied, the frequency of inv 3 proved to be highest in Russians $(6.0 \%)$, this inversion occurring even in homozygous forms $(0.5 \%)$ in this sample. Among the eight populations of Asia Mongoloids studied, this inversion was observed in only five of them, with a frequency ranging from $0.3 \%$ to $3.0 \%$. We explained this fact by the presence of a European "admixture" in their gene stock that was due either to their ethnic composition (the Kazakhs and the Kyrgyz) or to a definite stage of their political history in the past (Mongolians, the Chukchi, the Yakut), i.e., to the forefather effect (Ibraimov, 2010; Ibraimov \& Mirrakhimov, 1982a,b,c, 1985; Ibraimov et al., 1982, 1986). There is no other explanation for the fact that among 400 Japanese (Yamada \& Hasegawa, 1978), 124 Chinese, 120 Khakass, and two Kyrgyz populations of Pamir and Tien-Shan not a single case of such inversion was found. Furthermore, this inversion was absent in 148 Mozambiquan, 132 Angolan, 34 Zimbabwean and 13 Guinea-Bissau natives whom we studied. However, we found inv 3 among 52 Ethiopians (2.9\%) in whose gene stock the existence of a Europoid component is universally recognized.

Kurmanova (1991) studied 277 mountaineers of the Russian nationality at whom inv 3 was met at 23 individuals, and its frequency in the sampling was comparable to that in the control (6.8 \% and $6.0 \%$, accordingly). Thus, under this quantitative characteristic of chromosomal Q-HRs variability these two samplings of the Russian did not differ essentially. In other two groups of mountaineers ("metises" and the mixed group) inv 3 was met with frequency of $4.8 \%$ ( 3 individuals) and $4.4 \%$ (2 individuals), accordingly. Unfortunately, in none case she did not manage to carry out the family analysis. Nevertheless, the existence of inv 3 in the metises group it is possible to explain for that they have, at least, Russian as one of the parents. Both individuals with inv 3 in the mixed group as 
appeared to be Caucasoids, that once again testifies in favor of the assumption that inv 3 is the original "Caucasoid" marker.

In connection with the aforementioned, we consider that the inverted chromosome 3 (having in mind its pericentric inversion of Q-heterochromatin segment) is the original "Caucasoid" cytogenetic marker; and under frequency of its occurrence in the sampling, it is possible to judge of existence of European "impurity" in this or that population (Ibraimov \& Mirrakhimov, 1982a,b,c, 1985; Ibraimov et al., 1990, 1991). Our conclusions were completely confirmed by Rossi (1985) at research of some the Mexican populations. Thereupon, we think it is interesting to use this cytogenetic marker of ethnic anthropology in study of intensity of process metisation in a modern society where there is a mixture of various racial, national and ethnic groups as it is possible to define precisely the inv 3 frequencies in initial populations.

Thus, to summarize the results of researches where for finding-out the possible role of chromosomal Q-HRs in the human life activity we attached paramount significance to a place of their localization in karyotype, it is possible to consider, that as a whole they were useful and instructive.

Now, let's proceed to the approach where chromosomal Q-HRs is considered as a single structural-and-functional system in the human genome and regard as of paramount importance the total quantity, instead of localization of Q-heterochromatin segments in the karyotype. At this, if it concerns a concrete individual, then the important criterion to estimate variability of chromosomal Q-HRs their number (from 0 to 10) is considered in karyotype and if it concerns population, then the mean number of chromosomal Q-HRs per individual, as determined by dividing the total number of Q-HRs detected in a given sample by the number of individuals studied.

The assumption of absence of Q-HRs locus specificity, revealed by Q-staining, we stated on the basis of that observation, that at increase or decrease of an mean number of Q-HRs per an individual in populations there is a proportional increase or decrease in frequency of Q-variants on all Q-polymorphic loci simultaneously (Ibraimov, 1993; Ibraimov et al., 1986). In particular, it has appeared, that if to range all samples as the mean number of Q-HRs increase; and to execute the same operation with frequencies of Q-variants on seven Q-polymorphic autosomes, then distribution of populations on frequencies of Q-variants in these autosomes, as a whole, corresponds to their distribution on the mean number of Q-HRs calculated per individual in populations. The same was defined by us at the analysis of data from all other researchers (Buckton et al., 1976; Lubs et al., 1977; Kalz et al., 2005), revealed in the conditions of the same laboratory the interpopulation distinctions on the mean numbers of Q-HRs (Ibraimov, 1993, 2010).

In favor of the assumption about locus specificity absence in chromosomal Q-HRs variants the following testify: 1) despite the fact that in the human karyotype there are 25 loci where chromosomal Q-HRs could potentially be found, in reality the maximal number of Q-HRs does not exceed 10 (Yamada \& Hasegawa, 1978; Al-Nassar et al., 1981; Ibraimov \& Mirrakhimov, 1985); 2) in human populations the number of Q-HRs in the karyotype usually ranges from 0 to 10 (Ibraimov \& Mirrakhimov, 1985) without visible phenotypic effects; 3) distribution of Q-HRs in a population is near normal (Ibraimov et al., 1986, 1990, 1991); 4) at the population level the distribution of Q-HRs on seven Q-polymorphic autosomes is uneven, the greatest number of Q-HRs is found on chromosomes 3 and 13 (over 50\%), the rest are more or less evenly distributed on the other five autosomes (Ibraimov, 1993, 2010); 5) human populations do not differ from each other in the relative content of Q-HRs on seven autosomes (the portions of Q-HRs on autosomes 3, 4, 13, 14, 15, 21 and 22 on average are $25.5 \%, 3.5 \%, 30.7 \%, 8.6 \%, 12 \%$, $10.6 \%$ and $9.1 \%$, respectively) (Ibraimov, $1993 ; 2010 ; 2011) ; 6$ ) the quantitative content of chromosomal Q-HD s in the population genome is best determined by the value of the mean number of Q-HRs per individual ( $x$ ) (McKenzie \& Lubs, 1975; Yamada \& Hasegawa, 1978; Al-Nassar et al., 1981_- Ibraimov \& Mirrakhimov, 1982a,b,c, 1985; Ibraimov et al., 1986, 1990, 1991); 7) decreases and increases in $x$ in a population are due to simultaneous but proportional decreases or increases in the absolute number of Q-HRs on all the seven Q-polymorphic autosomes (Ibraimov, 1993; Ibraimov et al., 1986; 1990); 8) there are significant interpopulation differences in the quantitative content of chromosomal Q-HRs in the population genome (Buckton et al., 1976; Lubs et al., 1977; Ibraimov \& Mirrakhimov, 1982a,b,c; Ibraimov et al., 1982, 1990, 1991; Kalz et al., 2005); 9) these differences proved to be related to features of the ecological environment of the place of permanent residence and not to the racial and ethnic composition of the populations (Ibraimov and Mirrakhimov, $1982 \mathrm{a}, \mathrm{b}, \mathrm{c} ; 1985$; Ibraimov et al., 1982, 1986, 1990, 1991, 2013); 10) changes in the amount of Q-HRs in the population genome have a tendency towards a decrease from southern geographical latitudes to northern ones, and from low-altitude latitudes to high-altitude ones (Ibraimov \& Mirrakkimov, 1982a,b,c, 1985; Ibraimov et al., 1982, 1990, 1991, $1997,2013) ; 11$ ) both decreases and increases of the $x$ value are as a rule accompanied by narrowing or widening of the range of variability in the number of Q-HRs in a population (Ibraimov, 1993, 2010); 12) segregation of individuals in a human population with different number of Q-HRs in the karyotype (from 0 to 10 ) is due to the fact 
that Q-HRs are unevenly distributed on seven potentially Q-polymorphic autosomes (Ibraimov, 1993, 2010); 13) males in a population differ from each other in the size of the Q-heterochromatin segment of the Y chromosome (Paris C^nference, 1971, 1975; Yamada \& Hasegawa, 1978; Ibraimov \& Mirrakhimov, 1985); 14) in different age groups $x$ values differ, the greatest number of Q-HRs is characteristic of newborns, while the least number - in elderly subjects (Buckton et al., 1976; Ibraimov et al., 2014); 15) in the first days, weeks, months and years of life, ceteris paribus, among healthy children the infants often die with the greatest number of Q-HR in genome (Ibraimov \& Karagulova, 2006); 16) individuals that are capable to adapt to the extreme climate of high altitudes (e.g. mountaineers) and to that of the Far North (e.g. borers - oil industry workers of the Jamal peninsula, Eastern Siberia) have extremely low numbers of Q-HRs in their genome (Ibraimov et al., 1986, 1990, 1991); 17) individuals with a lesser number of Q-HRs in their genome proved to be prone to alcoholism and obesity, while those with great number of Q-HRs - to drug addiction (Ibraimov, 2010; 2015); 18) Q-HR on the Y chromosome is the largest in the human karyotype, and its size, on average, is twice larger than all the Q-HRs on autosomes, taken together (ISCN, 1978; Ibraimov \& Mirrakhimov, 1985); 19) Q-heterochromatin on the Y chromosome, being the largest in the human genome, - mehow "restricts" the total content of Q- HR on the autosomes in males. On the population level the value of $x$ is influenced by the amount of Q-HR on the Y chromosome - for example in samples of males with great blocks of Q-heterochromatin on the Y chromosome the mean number of Q-HRs on their autosomes is lower and vice versa (Ibraimov et al., 2000); 20) there is some mechanism that compensates for the deficiency of Q-heterochromatin material in the female genome due to the lack of Y chromosome in their karyotype by increasing the amount of Q-HRs on autosomes. This pattern persists regardless of age and racial-ethnic characteristics of human populations (Ibraimov et al., 2014a); and at last, 21) individuals in population truly differ from each other in body heat conductivity and its level depends on the amount of chromosomal Q-HRs in human genome (Ibraimov et al., 2014b).

As it is seen from above stated, the non-locus specific approach has allowed clarifying some regularities in the distribution of chromosomal Q-HRs at level of populations, and some effects of this type constitutive heterochromatin upon the human life activity.

Of course we are far from the idea that the above listed regularities and effects are limited by the role of chromosomal Q-HRs in the human genome. It will not be surprising if it turns out that Q-HRs has many other important effects on life activity of three higher primates.

\section{Concluding remarks}

Despite the fact that chromosomal C- and Q-heterochromatin are defined by a single term, "constitutive heterochromatin", they are undoubtedly significantly different intrachromosomal structures. There are several significant differences between them: C-heterochromatin is found in the chromosomes of all the higher eukaryotes, while Q-heterochromatin - only in man (Homo s. sapiens), the chimpanzee (Pan troglodytes) and gorilla (Gorilla gorilla) (Pearson, 1973, 1977). C-HRs is known to be invariably present in all the chromosomes of man, varying mainly in size and location (inversion). Q-HRs variability can be found in man only on seven autosomes $(3,4,13,14,15,21$ and 22), as well as on chromosome Y. Chimpanzees have Q-HRs on five autosomes $(14,15,17,22$ and 23), while in gorillas they are present on eight $(3,12,13,14,15,16,22$ and 23) and on chromosome Y (Paris Conference, 1971; 1975; Chiarelli \& Lin, 1972; Pearson, 1973, 1977; Dutrillaux et al., 1981). Chromosomal Q-HRs is subject to considerably greater variability in any population as compared to C-HRs. Erdtmann (1982) emphasized that "recent analyses... show a great population and evolutionary stability of C-band homeomorphisms... From interpopulation comparisons, C-band means show a tendency to maintain a constant amount of constitutive heterochromatin".

The most remarkable in all this, to our opinion, is the fact of Q-heterochromatin detected in genome of only three higher primacies. This circumstance, in its time, made some researchers to search for relation between Q-HRs variants and the human intelligence. Thus, Lubs et al. (1977) were unable to find any correlation between IQ and the distribution pattern of Q-HRs variants in a group of children aged 7-8 years. Schwinger and Wehner (1976) were also unable to find any correlation with the frequency of Q-HRs in seven autosomes of 89 randomly selected normal subjects and 244 patients with various types of mental disorders. Tharapel and Summit (1978) also found no statistically significant differences in Q-HRs polymorphism between 200 mentally deficient subjects and 200 controls. The results of Matsuura et al. (1979), obtained in patients with different forms of mental deficiency, are not at variance with these observations.

In due time we have supposed to consider chromosomal Q-HRs as a single structural-and-functional system. Usually the system is meant as an aggregate singled out real or imagined elements in any way from other world (Bertalanffy, 1968). It is possible to consider this aggregate as a biological system, if: 1) each of elements is 
indivisible further (not in the physical sense, but conditionally); 2) it co-operates with world around as whole; 3 ) the relations existing between elements of the singled out aggregate are set, and at evolution between them an unequivocal conformity remains, that is there is some orderliness.

Indivisibility of Q-HRs, located in 12 polymorphic loci of seven pairs of autosomes and on the distal part of Y chromosome results from specificity of cytochemical methods used now for their revealing (Caspersson et al., 1970; Paris Conference, 1971; 1975; ISCN, 1978). As for the second requirement it basically is reduced to the following: as closer to a place of human dwelling to the northern pole, as well as with increase in height of the location above the sea level, the amount of Q-heterochromatin decreases in the human population genome, irrespective of race-ethnic features of populations, and reduction of the content of Q-HRs occurs proportionally on all Q-polymorphic autosomes. Thus, if to require, that elements of the assumed system would co-operate with the world around as a whole unit, the facts of proportional decrease or increase in quantity of Q-HRs on Q-polymorphic autosomes in a human population gene pool, depending on features of the ecological environment round their dwelling, apparently, convincingly enough testify in favor of the aforementioned representation (Ibraimov, 1993, 2010, 2011, 2015; Ibraimov et al., 1986).

Concerning the third requirement, probably, it is worth to notice once again, that:

1) portion of Q-HRs variants in 12 Q-polymorphic loci of seven pairs of autosomes in the populations, expressed in percentage of number of the Q-variants revealed in this or that sampling, remains comparable, irrespective of the values of mean numbers of Q-HRs calculated per individual in populations (Ibraimov, 1983, 1993, 2010, 2011);

2) even in those populations where the mean number of Q-HRs per individual are very low, there is not the disappearance of Q-heterochromatin on the autosomes with low frequency of Q-variants and, moreover, the contribution of Q-high polymorphic, and the Q-low polymorphic chromosomes in the total pool of Q-heterochromatin material remains quite comparable in different samplings, regardless their racial or ethnic origin or characteristics of their permanent residence place (Ibraimov et al., 1986, 1990, 1991, 2013).

3) the distribution of the numbers of Q-HRs in the population always has the form close to a normal distribution (Ibraimov, 1993, 2010). All this is possible if the studied genetic material in the human genome will behave at the level of populations as a single self-sustaining structural and functional system (Ibraimov, 1993; Ibraimov et al., 1990).

The bulk of the data obtained on over of half a century empirical observations and analytical studies, described above, have allowed us to hypothesize that 'of primary importance to an individual is the dose and not the location of Q-variants' and to assume that the possible effect of chromosomal Q-HRs in the human body depends on its total amount in the genome (Ibraimov et al., 1986). And really it turned out that, for example, the level of human body heat conductivity directly depends on amount of chromosomal Q-HRs in his genome (Ibraimov et al., 2014b). Thus, we have concluded that all of the existing methods to analyze chromosomal Q-HRs is the most fruitful approach when this type of constitutive heterochromatin is considered as a single self-sustaining structural and functional genetic system in human genome.

\section{Acknowledgements}

I apologize to those authors whose work is not cited or cited only through reviews. The reason for this is only the space limitations.

\section{References}

Allderdice, P. W. (1973). Identification of the location of a crossover in a pericentric inversion heterozygote which resulted in a duplication deficient chromosome 3. Am J Hum Genet, 25, 11.

Al-Nassar, K. E, Palmer, C. G., Connealy, P. M., \& Pao-Lo, Y. (1981). The genetic structure of the Kuwaiti population. II. The distribution of Q-band chromosomal heteromorphisms. Hum Genet, 57, 423-427.

Bertalanfy, V. L. (1968). General System Theory. Foundations, Development, Applications. New York.

Bhasin, M. K. (2007). Human population cytogenetics. A review. In V, Bhasin \& M. K. Bhasin (Eds), Anthropology today: trends, scope and applications. Delhi, India: Kamla-Raj Enterprises.

Buckton, K. E., O'riordan, M. L., Jacobs, P. A., Robinson, J. A., Hill, R., \& Evans, H. J. (1976). C - and Q - band polymorphisms in the chromosomes of three human populations. Annals of human genetics, 40(1), 99-112.

Caspersson, T., Zech, L., \& Johansson, C. (1970). Differential binding of alkilating fluorochromes in human chromosomes. Exp Cell Res, 60, 315-319. 
Chiarelli, B., \& Lin, C. C. (1972). Comparison of fluorescence patterns in human and chimpanzee chromosomes. Genet Phaenen, 15, 103-106.

Décsey, K., Bellovits, O., \& Bujdoso, G. M. (2006). Human chromosomal polymorphism in Hungarian sample. Int J Hum Genet, 6(3), 177-183.

Dutrillaux, B., Counturier, J., \& Viegas-Pèquignot, E. (1981). Chromosomal evolution in primates. In M. D. Bennet, M. Boboraw, \& G. M. Herwitt (Eds.), Chromosomes today (vol 7, pp. 176-191). New-York.

Erdtmann, B. (1982). Aspects of evaluation, significance, and evolution of human C-band heteromorphism. Hum Genet, 61, 281-294.

Evans, H. J., Buckton, K., \& Sumner, A. T. (1971). Cytological mapping of human chromosomes: results obtained with quinacrine fluorescence and the acetic-saline-giemsa techniques. Chromosoma, 35, 310.

Fogle, T. A., \& McKenzie, W. H. (1980). Cytogenetic study of a large black kindred: inversions, heteromorphisms and segregation analysis. Hum. Genet., 55, 345.

Geraedts, J. P. M., \& Pearson, P. L. (1974). Fluorescent chromosome polymorphism: frequencies and segregation in a Dutch population. Clin Genet, 6, 247-257.

Heitz, E. (1934). Die Somatische heteropyknose bei Drosophila melanogaster und ihre genetische Bedeutung. $Z$. Zellfosch, 20, 237-287.

Heitz, E. (1935). Chromosomen structur und Gene. Ztschr induct Abstammungs und vererbungslehre, 70, $402-447$.

Heitz, E. (1928). Das Heterochromatin der Moose. J Jahrb Wisenschs Bot, 69, 762-818.

Ibraimov, A. I, Akanov, A. A., Meymanaliev, T. S., Smailova, R. D., \& Baygazieva, G. D. (2014a). Chromosomal Q-heterochromatin and age in human population. J Mol Biol Res, 4(1), 1-9.

Ibraimov, A. I. (1993). The origin of modern humans: a cytogenetic model. Hum Evol, 8, 81-91.

Ibraimov, A. I. (2010). Chromosomal Q-heterochromatin regions in populations and human adaptation. In: MK Bhasin, C Susanne (Eds.): Anthropology Today: Trends and Scope of Human Biology. Delhi: Kamla- Raj Enterprises, pp. 225-250.

Ibraimov, A. I. (2011). Origin of modern humans: a cytogenetic model. Hum Evol, 26(1-2), 33-47.

Ibraimov, A. I. (2014). Chromosomal Q-heterochromatin and sex in human population. J Mol Biol Res, 4(1), $10-19$.

Ibraimov, A. I. (2015). Heterochromatin: The visible with many invisible effects. Global Journal of Medical Research (C), 15(3), 7-32 (Version 1.0).

Ibraimov, A. I., \& Kagagulova, G. O. (2006). Chromosomal Q-heterochromatin variability in neonates deceased during first year of age. Int J Hum Genet, 6(4), 281-285.

Ibraimov, A. I., \& Mirrakhimov, M. M. (1982a). Human chromosomal polymorphism. III. Chromosomal Q-polymorphism in Mongoloids of northern Asia. Hum Genet, 62, 252-257.

Ibraimov, A. I., \& Mirrakhimov, M. M. (1982b). Human chromosomal polymorphism. IV. Chromosomal Q-polymorphism in Russians living in Kyrghyzia. Hum Genet, 62, 258-260.

Ibraimov, A. I., \& Mirrakhimov, M. M. (1982c). Human chromosomal polymorphism. V. Chromosomal Q-polymorphism in African populations. Hum Genet, 62, 261-265.

Ibraimov, A. I., \& Mirrakhimov, M. M. (1985). Q-band polymorphism in the autosomes and the Y chromosome in human populations. In: Progress and Topics in Cytogenetics. The $\mathrm{Y}$ chromosome. Part A. Basic Characteristics of the Y chromosome. Ed. by A. A. Sandberg. Alan R. Liss Inc., New York, pp.213-287.

Ibraimov, A. I., Akanov, A. A., Meimanaliev, T. S., Sharipov, K. O., Smailova, R. D., \& Dosymbekova, R. (2014b). Human Chromosomal Q-heterochromatin Polymorphism and Its Relation to Body Heat Conductivity. Int J Genet, 6(1), 142-148.

Ibraimov, A. I., Akanov, A. A., Meymanaliev, T. S., Karakushukova, A. S., Kudrina, N. O., Sharipov K. O., \& Smailova, R. D. (2013). Chromosomal Q-heterochromatin polymorphisms in 3 ethnic groups (Kazakhs, Russians and Uygurs) of Kazakhstan. Int J Genet, 5(1), 121-124. 
Ibraimov, A. I., Axenrod, E. I., Kurmanova, G. U., \& Turapov, D. A. (1991). Chromosomal Q-heterochromatin regions in the indigenous population of the northern part of West Siberia and new migrants. Cytobios, 67, 95-100.

Ibraimov, A. I., Karagulova, G. O., \& Kim, E. Y. (1997). Chromosomal Q-heterochromatin regions in indigenous populations of the Northern India. Ind J Hum Genet, 3, 7-81.

Ibraimov, A. I., Karagulova, G. O., \& Kim, E. Y. (2000). The relationship between the Y chromosome size and the amount of autosomal Q-heterochromatin in human populations. Cytobios, 102, 35-53.

Ibraimov, A. I., Kurmanova, G. U., Ginsburg, E. K. h., Aksenovich, T. I., \& Axenrod, E. I. (1990). Chromosomal Q-heterochromatin regions in native highlanders of Pamir and Tien-Shan and in newcomers. Cytobios, 63, 71-82.

Ibraimov, A. I., Mirrakhimov, M. M., Axenrod, E. I., \& Kurmanova, G. U. (1986). Human chromosomal polymorphism. IX. Further data on the possible selective value of chromosomal Q-heterochromatin material. Hum Genet, 73, 151-156.

Ibraimov, A. I., Mirrakhimov, M. M., Nazarenko, S. A., Axenrod, E. I., \& Akbanova, G. A. (1982). Human chromosomal polymorphism. I. Chromosomal Q-polymorphism in Mongoloid populations of Central Asia. Hum Genet, 60, 1-7.

Inuma, K., Matsunaga, E., \& Nakagome, J. (1973). Polymorphism of C and Q bands in human chromosomes. Annu Rep Natl Genet (Japan), 23, 112.

ISCN. (1978). An international system for human cytogenetic nomenclature. Report of the standing committee on human cytogenetic nomenclature. Cytogenet Cell Genet, 21, 313(1)-404(92).

Jacobs, P. A. (1977). Human chromosome heteromorphisms (variants). In: Progress in Medical Genetics, Vol. II. Steinberg A.G., Beam A.G. and Motulsky A.G. (eds). Philadelphia. Saunders, pp. 251-272.

John, B. (1988). The biology of heterochromatin. In: Heterochromatin: Molecular and Structural Aspects. Edited by R. S. Verma. Cambridge University Press Cambridge, New York, New Rochelle, Melbourne, Sydney.

Kalz, L., Kalz-Fuller, B., Hedge, S., \& Schwanitz, G. (2005). Polymorphism of Q-band heterochromatin; qualitative and quantitative analyses of features in 3 ethnic groups (Europeans, Indians, and Turks). Int J Hum Genet, 5(2), 153-163.

Kivi, S. Y., \& Mikelsaar, A. V. N. (1981). Variants of chromosomal Q- and C-bands in patients with breast or ovarian cancer. In Prokofyeva-Belgovskaya AA, Zakharov AF 9eds): Human Chromosomal Polymorphism. Moscow, Meditsina, p.196.

Lubs, H. A., Patil, S. R., Kimberling, W. J., Brown, J., Hecht, F., Gerald, P., \& Summitt, R. L. (1977). Racial differences in the frequency of Q- and C-chromosomal heteromorphism. Nature, 268, 631-632.

Matsuura, J. S., Mayer, M., \& Jacobs, P. A. (1979). A cytogenetic survey of an institution for the mentally retarded. III. Q-band chromosome heteromorphisms. Hum Genet, 52, 203-210.

McKenzie, W. H., \& Lubs, H. A. (1975). Human Q and C chromosoma1 variations: distribution and incidence. Cytogenet Cell Genet, 14, 97-115.

Mikelsaar, A. V. N., Ilus, T., \& Kivi, S. (1978). Variant chromosome 3 (inv. 3) in normal newborns and parents and in children with mental retardation. Hum Genet, 41, 109-113.

Mikelsaar, A. V. N., Kivi, S. Y., \& Ilus, T. A. (1981). Chromosomal variants and human growth. In A. A. Prokofyeva-Belgovskaya \& A. F. Zakharov (Eds.), Human Chromosomal Polymorphism. Moscow, Meditsina, p.107.

Mikelsaar, A. V. N., Kääosaar, M. E., \& Tüür, S. J. (1975). Human karyotype polymorphism. III. Routine and fluorescence microscopic investigation of chromosomes in normal adults and mentally retarded children. Humangenetik, 26, 1-23.

Mikelsaar, A. V. N., Viikmao, M. N., Tuur, S. J., \& Kaosaar, M. E. (1974). Human karyotype polymorphism. II. The distribution of individuals according to the presence of brilliant bands in chromosomes 3, 4 and 13 in a normal adult population. Humangenetik, 23, 59-63.

Müller, H. J., Klinger, H. P., \& Glasser, M. (1975). Chromosome polymorphism in a human newborn population. II. Potentials of polymorphic chromosome variants for characterizing the idiograms of an individual. Cytogenet Cell Genet, 15, 239-255. 
Nazarenko, S. A. (1987). Age dynamics of fluorescent polymorphism in human chromosomes. Cytol Genet (Russian), 21, 183-186.

Paris Conference. (1971) and Supplement (1975). Standartization in human cytogenetics. Birth Defects: Original Article Series, XI, 1-84. The National Foundation, New York.

Pearson, P. L. (1973). Banding patterns chromosome polymorphism and primate evolution. Progress in Medical Genetics, 2, 174-197.

Pearson, P. L. (1977). The uniqueness of the human karyotype. In T. Caspersson \& L. Zech (Eds.), Chromosome identification: technique and applications in biology and medicine. New York, London: Academic Press.

Phillips, R. B. (1977). Inheritance of Q and C-band polymorphisms. Can J Genet Cytol, 19, 405- 415.

Prokofyeva-Belgovskaya, A. A. (1986). Heterochromatin Regions of Chromosomes (Russian). Nauka, Moscow.

Robinson, J. A., Buckton, K. E., \& Spowart G. (1976). The segregation of human chromosome polymorphisms. Ann Hum Genet, 40, 113-121.

Rossi, S. L. (1985). Polymorphismos chromosomicos: metodologia y aplicacion en diagnostico citogenetico prenatal: Tesis Profecional. Mexico.

Schmid, W. (1967). Heterochromatin in mammals. Arch. Julius Klaus-Stiftung Vererb, 42, 1-60.

Schnedl, W. (1971). Banding pattern of human chromosomes. Nature, 233, 93.

Schwinger, E., \& Wehner, H. (1976). Frequency of chromosomal fluorescence polymorphism in normal persons and in clinical patients with diagnosed chromosome aberrations. Hum Genet, 32, 115-119.

Soudek, D., \& Sroka, H. (1978). Inversion of "fluorescent" segment in chromosome 3: A polymorphic trait. Hum Genet, 44, 109-115.

Soudek, D., O.'Shaunghnesky, L. P., \& McCreary, B. D. (1974). Pericentric inversion of "fluorescent" segment in chromosome No 3. Humangenetik, 22, 343-346.

Stahl, A., \& Hartung, M. I. (1981). L'heterochromatine. Ann. Genet., 24, 69-77.

Stanyon, R., Studer, M., Dragone, A., De Benedicts, G., \& Brancati, C. (1988). Population cytogenetics of Albanians in the province of Cosenza (Italy): frequency of Q and C band variants. Int J Anthropol, 3(1), 14-29.

Tharapel, A. T., \& Summit, R. L. (1978). Minor chromosome variations and selected homeomorphisms in 200 unclassifiable mentally retarded patients and 200 normal controls. Hum Genet, 41, 121-130.

Tupitsina, L. P., \& Stobetsky, V. I. (1980). Segregation of chromosomal Q-polymorphic variants. Genetics (USSR), 16, 727.

van Dyke, D. L., Palmer, C. G., Nance, W. E., \& Pao-Lo, Y. (1977). Chromosome polymorphism and twin zygosity. Am J Hum Genet, 29, 431-447.

Verma, R. S. (1988). Heteromorphism of heterochromatin. In: Heterochromatin: Molecular and Structural Aspects. Edited by R. S. Verma. Cambridge University Press, Cambridge, New York, New Rochelle, Melbourne, Sydney.

Verma, R. S., \& Dosik, H. (1980a). Human chromosomai heteromorphisms: nature and clinical significance. Int Rev Cytol, 62, 361-383.

Verma, R. S., \& Dosik, H. (1980b). Human chromosomal heteromorphisms in American blacks. I. Structural variability of chromosome 3 . J Hered, 71, 441.

Yamada, K., \& Hasegawa, T. (1978). Types and frequencies of Q-variant chromosomes in a Japanese population. Hum Genet, 44, 89-98.

Kurmanova, G. U. (1991). Izmenchivosti Q-heterochrominovykh rayonov khromosom v svyazy s adaptatsiei cheloveka k vysokogoryu. Thesis. SB AS USSR. Novosibirsk.

\section{Copyrights}

Copyright for this article is retained by the author(s), with first publication rights granted to the journal.

This is an open-access article distributed under the terms and conditions of the Creative Commons Attribution license (http://creativecommons.org/licenses/by/3.0/). 